\title{
Accuracy of the estimated prevalence of obesity from self reported height and weight in an adult Scottish population
}

\author{
Caroline Bolton-Smith, Mark Woodward, Hugh Tunstall-Pedoe, Caroline Morrison
}

\begin{abstract}
Study objective-To determine whether self reported heights and weights from Scottish adults can provide an accurate assessment of obesity prevalence in the population.

Design-Standardised clinic measurements of weight and height were compared against self reported values on a postal questionnaire in the fourth Scottish MONICA cross sectional study.

Setting-A sex and five year age band stratified random population sample drawn from general practitioner registers in north Glasgow in 1995. Response rate $63 \%$ for men and $62 \%$ for women.
\end{abstract}

Participants-A total of 865 men and 971 women aged between 25 and 64 years.

Results-Men and women under-reported their weight by a mean (SD) of $0.63(3.45)$ $\mathrm{kg}$ and $0.95(2.64) \mathrm{kg}$ respectively, and their height by a mean (SD) of 1.3 (2.50) $\mathrm{cm}$ and $1.7(2.37) \mathrm{cm}$ respectively. Estimated body mass index, BMI $\left(\mathrm{kg} / \mathrm{m}^{2}\right)$ varied from true (measured) BMI by +0.19 (1.40) for men and by +0.17 (1.34) for women. The only age/sex group in which BMI was under-estimated from self reports (mean 0.2 ) was the 55-64 year old women. Prediction equations that explained $90 \%$ (men) and $88 \%$ (women) of the difference between self reported and measured height included age and self reported weight. The equivalent prediction equations for weight explained $93 \%$ of the difference between self reported and measured weight for men and included smoking and diabetic status, while for women $96 \%$ of the variance was explained with no further variables being significant. Sensitivity and specificity for determining clinical obesity (BMI $\geqslant 30$ ) were $83 \%$ and $96 \%$ respectively for men, and $89 \%$ and $97 \%$ for women.

Conclusions-This Scottish population was unique in the under-reporting of height as well as weight, which resulted in BMI estimates with low error. These data suggest that self reported weights and heights would be satisfactory for the monitoring of obesity prevalence in Scotland.

(F Epidemiol Community Health 2000;54:143-148)

Knowledge of height and weight in a population is relevant to general health and nutrient status, specific obesity assessment and risk of other diseases. Self reported height and weight provide a cost effective assessment of these variables and thus have been used in numerous epidemiological studies $^{1-5}$ and in other contexts. ${ }^{6}$ In Western society, thinness and tallness are generally seen as ideals. ${ }^{78}$ This may, at least partly, account for the general finding of under-reporting of weight and over-reporting of height in studies. ${ }^{25}$ 9-11 $^{2}$ This has led to under-estimation of body mass index, $\mathrm{kg} / \mathrm{m}^{2}$ (BMI), the most commonly used measure of obesity, and consequent lack of confidence in this approach for assessing obesity prevalence. $^{2} 1011$

The validity of self reported weight and height had not previously been reported in a Scottish population, and neither had possible sub-population biases relating to smoking and ill health been considered in conjunction with age, gender and BMI. These issues are considered here, using data from a large, random population sample: the fourth Scottish MONICA survey of 1995.

\section{Methods}

The MONICA Project was an international collaborative study of trends and determinants of cardiovascular disease. ${ }^{12}$ The fourth Scottish MONICA survey of 1995 consisted of 865 men and 971 women aged 25-64 who were randomly sampled from the lists of general practitioners serving the north Glasgow catchment population. The response rate was $63 \%$ in men and $62 \%$ in women. Those participating were sent a postal questionnaire (Personal Health Record) to complete and were invited to attend at a screening clinic. The questionnaire was sent out two weeks before the clinic appointment date. Ethics approval was granted by the relevant committees and signed, informed consent was obtained from each participant.

The Personal Health Record included questions on current height and weight (instructions: minus shoes and in light indoor clothing), as well as a wide range of sociodemographic, medical history, dietary, physical activity and tobacco consumption questions. At a clinic, height and weight were measured according to a standard protocol by a team of trained nurses, and a blood sample was taken. Height was measured, without shoes, to the nearest centimetre, using a stadiometre (Holtain, UK) that was checked daily for accuracy. Weight was measured, without shoes and heavy outer garments, to the nearest $0.1 \mathrm{~kg}$, using scales (Seca, Germany) that were calibrated between each weighing with 
Table 1 Summary statistics by gender

\begin{tabular}{|c|c|c|c|c|c|c|c|c|c|c|c|c|}
\hline & \multicolumn{6}{|l|}{ Men } & \multicolumn{6}{|l|}{ Women } \\
\hline & Numbert & $Q_{1}$ & $Q_{2}$ & $Q_{3}$ & mean & $S D$ & Number & $Q_{1}$ & $Q_{2}$ & $Q_{3}$ & mean & $S D$ \\
\hline \multicolumn{13}{|l|}{ Height $(\mathrm{cm})$} \\
\hline Measured $\left(\mathrm{H}_{\mathrm{M}}\right)$ & 865 & 168 & 172 & 177 & 172.3 & 6.99 & 969 & 155 & 160 & 164 & 159.7 & 6.38 \\
\hline Self reported $\left(\mathrm{H}_{\mathrm{R}}\right)$ & 819 & 165 & 170 & 175 & 171.1 & 7.19 & 929 & 154 & 158 & 163 & 158.1 & 6.66 \\
\hline Difference $\left(\mathrm{H}_{\mathrm{D}}=\mathrm{H}_{\mathrm{M}}-\mathrm{H}_{\mathrm{R}}\right)$ & 819 & 0 & 1 & 3 & $1.3^{\star \star}$ & 2.50 & 928 & 0 & 2 & 3 & $1.7^{\star \star}$ & 2.37 \\
\hline $\begin{array}{l}\% \text { difference }\left(100 \mathrm{H}_{\mathrm{D}} / \mathrm{H}_{\mathrm{M}}\right) \\
\text { Weight }(\mathrm{kg})\end{array}$ & 819 & 0.0 & 0.6 & 1.6 & 0.7 & 1.45 & 928 & 0.0 & 1.2 & 1.9 & 1.0 & 1.51 \\
\hline Measured $\left(\mathrm{W}_{\mathrm{M}}\right)$ & 861 & 69.3 & 78.0 & 87.0 & 78.85 & 13.927 & 968 & 57.7 & 64.4 & 73.7 & 67.24 & 14.381 \\
\hline Self reported $\left(\mathrm{W}_{\mathrm{R}}\right)$ & 783 & 69.9 & 77.2 & 86.3 & 78.08 & 13.275 & 872 & 57.2 & 63.6 & 71.7 & 65.80 & 13.820 \\
\hline Difference $\left(\mathrm{W}_{\mathrm{D}}=\mathrm{W}_{\mathrm{M}}-\mathrm{W}_{\mathrm{R}}\right)$ & 779 & -1.3 & 0.5 & 2.5 & $0.63^{\star \star}$ & 3.451 & 870 & -0.4 & 0.8 & 2.1 & $0.95^{\star \star}$ & 2.636 \\
\hline $\begin{array}{l}\% \text { difference }\left(100 \mathrm{~W}_{\mathrm{D}} / \mathrm{W}_{\mathrm{M}}\right) \\
\text { Body mass index }\left(\mathrm{kg} / \mathrm{m}^{2}\right)\end{array}$ & 779 & -1.7 & 0.6 & 3.0 & 0.6 & 4.51 & 870 & -0.6 & 1.2 & 3.1 & 1.3 & 3.78 \\
\hline Measured $\left(\mathrm{B}_{M}=\mathrm{W}_{M} / \mathrm{H}^{2}{ }_{M}\right)$ & 861 & 23.68 & 26.23 & 29.01 & 26.53 & 4.238 & 968 & 22.65 & 25.40 & 28.77 & 26.38 & 5.551 \\
\hline Self reported $\left(\mathrm{B}_{\mathrm{R}}=\mathrm{W}_{\mathrm{R}} / \mathrm{H}^{2}{ }_{\mathrm{M}}\right)$ & 769 & 23.74 & 26.10 & 29.27 & 26.67 & 4.083 & 862 & 22.73 & 25.35 & 29.04 & 26.38 & 5.451 \\
\hline Difference $\left(B_{D}=B_{M}-B_{R}\right)$ & 765 & -0.97 & -0.18 & 0.52 & $-0.19^{\star}$ & 1.403 & 860 & -0.88 & -0.25 & 0.49 & $-0.17^{\star}$ & 1.336 \\
\hline$\%$ difference $\left(100 \mathrm{~B}_{\mathrm{D}} / \mathrm{B}_{\mathrm{M}}\right)$ & 765 & -3.7 & -0.7 & 2.0 & -0.9 & 5.39 & 860 & -3.5 & -1.0 & 1.9 & -0.8 & 4.98 \\
\hline
\end{tabular}

†Sample size varied because of missing values; $\mathrm{Q}_{1-3}$, quartiles; ${ }^{\star} \mathrm{p}=0.0002,{ }^{\star \star} \mathrm{p}<0.0001$ significance of differences between measured and self reported values by paired $t$ test.

a $5 \mathrm{~kg}$ weight. Screeners were routinely tested for competence in height measurement by a senior nurse, who was responsible for adherence to the standard operating procedures.

The differences between measured (true) and self reported height and weight were assessed separately for each sex and the significance of the differences assessed by paired $t$ test. Within sex group, these differences were compared to a range of variables, thought to have a possible effect on recording accuracy. These variables were age, special diet (none/ slimming/other), self report of medical diagnoses of myocardial infarction (MI) and diabetes mellitus, smoking status (current/ex/ never) and serum cotinine (objective measure of current tobacco consumption ${ }^{13}$ ). Socioeconomic status assessed in three ways (manual/ non-manual occupational social class ${ }^{14}$; school versus further education attained; housing tenure as owner-occupier or renter) and physical activity by thirds of the physical activity ratio (PAR, questionnaire-based assessment of energy expenditure expressed as a multiple of calculated basal metabolic rate $^{15}$ ). Statistical analyses were carried out using general linear models, after first confirming that normal assumptions were justified. ${ }^{16}$

Prediction equations were computed for height and weight using self reported height and weight and all the prediction variables considered above. Separate model fitting exercises were carried out for men and women. When deriving the prediction equations for weight and height a $10 \%$ rather than a $5 \%$ level of significance was taken to protect against missing important effects. This can occur when the sample is very unevenly distributed, as occurred in some situations here. Any variable that was not significant $(p>0.1)$ in the presence of the others was dropped from the model.

\section{Results}

Table 1 shows the summary statistics for the height $(\mathrm{m})$, weight $(\mathrm{kg})$ and BMI $\left(\mathrm{kg} / \mathrm{m}^{2}\right)$ variables by sex group. Sample size variation occurred when missing values were present. Both men and women tended to underestimate their height and weight. In percentage terms, there was a similar degree of error in each. The net result was that the mean estimated BMI (from self reported weight and height) was slightly greater than true BMI: by 0.19 and 0.17 of a BMI unit for men and women respectively. The overall degree of error from self reporting was small: between $0.6 \%$ and $1.3 \%$ in the six cases shown in table 1. Histograms, which illustrated the differences between measured and self reported height and weight, have been published in abstract form. ${ }^{17}$

Table 2 shows differences between measured and self reported height, weight and estimated BMI by 10 year age group. Although there was no systematic trend by age, the oldest people (55-64 year olds) tended to underestimate their height least and their weight most, so that, on average, women in this age group uniquely under-estimated BMI.

Table 2 Mean (SD) height, weight and body mass index by 10 year age group

\begin{tabular}{|c|c|c|c|c|c|c|c|c|c|c|}
\hline & \multicolumn{5}{|l|}{ Men } & \multicolumn{5}{|l|}{ Women } \\
\hline & $\begin{array}{l}25-34 \\
(n=189)\end{array}$ & $\begin{array}{l}35-44 \\
(n=216)\end{array}$ & $\begin{array}{l}45-54 \\
(n=228)\end{array}$ & $\begin{array}{l}55-64 \\
(n=232)\end{array}$ & $p$ value & $\begin{array}{l}25-34 \\
(n=244)\end{array}$ & $\begin{array}{l}35-44 \\
(n=237)\end{array}$ & $\begin{array}{l}45-54 \\
(n=245)\end{array}$ & $\begin{array}{l}55-64 \\
(n=245)\end{array}$ & $p$ value \\
\hline \multicolumn{11}{|l|}{ Height (cm) } \\
\hline Measured $\left(\mathrm{H}_{\mathrm{M}}\right)$ & $174.0(7.9)$ & $173.3(7.4)$ & $171.3(5.8)$ & $170.9(6.5)$ & $<0.0001$ & $161.7(6.6)$ & $159.8(6.2)$ & $159.5(6.2)$ & $157.7(5.8)$ & $<0.0001$ \\
\hline Self reported $\left(\mathrm{H}_{\mathrm{R}}\right)$ & $172.7(8.4)$ & $171.6(7.4)$ & $170.1(6.0)$ & $170.3(6.8)$ & 0.0006 & $159.7(7.0)$ & $158.0(6.7)$ & $157.6(6.7)$ & $156.9(5.9)$ & $<0.0001$ \\
\hline $\begin{array}{l}\text { Difference }\left(\mathrm{H}_{\mathrm{M}}-\mathrm{M}_{\mathrm{R}}\right) \\
\text { Weight }(\mathrm{kg})\end{array}$ & $1.6(2.5)$ & $1.9(2.9)$ & $1.0(2.1)$ & $0.7(2.4)$ & $<0.0001$ & $2.1(2.4)$ & $2.0(2.2)$ & $1.7(2.3)$ & $0.9(2.4)$ & $<0.0001$ \\
\hline Measured $\left(\mathrm{W}_{\mathrm{M}}\right)$ & $77.4(13.6)$ & $79.8(14.4)$ & $79.2(14.1)$ & $78.7(13.4)$ & 0.36 & $64.6(13.8)$ & $67.1(14.2)$ & $69.0(14.8)$ & $68.4(14.4)$ & 0.003 \\
\hline Self reported $\left(\mathrm{W}_{\mathrm{R}}\right)$ & $76.8(13.0)$ & $78.7(14.0)$ & $78.4(13.1)$ & $78.3(12.9)$ & 0.52 & $63.2(12.7)$ & $66.0(14.2)$ & $67.6(14.2)$ & $66.5(13.9)$ & 0.006 \\
\hline $\begin{array}{l}\text { Difference }\left(\mathrm{W}_{\mathrm{M}}-\mathrm{W}_{\mathrm{R}}\right) \\
\text { Body mass index }\left(\mathrm{kg} / \mathrm{m}^{2}\right)\end{array}$ & $0.5(3.5)$ & $0.6(3.7)$ & $0.4(3.9)$ & $0.8(3.4)$ & 0.69 & $0.9(2.7)$ & $0.6(2.9)$ & $0.8(2.1)$ & $1.4(2.8)$ & 0.04 \\
\hline Measured $\left(B_{M}\right)$ & $25.5(3.7)$ & $26.6(4.4)$ & $27.0(4.5)$ & $26.9(4.0)$ & 0.001 & $24.7(5.1)$ & $26.3(5.4)$ & $27.2(5.9)$ & $27.4(5.4)$ & $<0.0001$ \\
\hline Self reported $\left(B_{R}\right)$ & $25.6(3.4)$ & $26.7(4.5)$ & $27.2(4.3)$ & $26.9(3.8)$ & 0.001 & $24.9(4.8)$ & $26.4(5.6)$ & $27.2(5.8)$ & $27.1(5.4)$ & $<0.0001$ \\
\hline Difference $\left(B_{M}-B_{R}\right)$ & $-0.3(1.3)$ & $-0.4(1.5)$ & $-0.2(1.6)$ & $-0.0(1.4)$ & 0.02 & $-0.3(1.3)$ & $-0.4(1.3)$ & $-0.3(1.2)$ & $0.2(1.5)$ & $<0.0001$ \\
\hline
\end{tabular}


The differences between measured and self reported height and weight and estimated BMI were not significantly different between occupational social class groups $(p=0.23)$, education level groups $(\mathrm{p}=0.34)$, housing tenure groups $(\mathrm{p}=0.45)$, special diet groups $(\mathrm{p}=$ $0.36)$, cotinine thirds $(\mathrm{p}=0.13)$ or PAR thirds $(\mathrm{p}=0.17)$. The smoking habit, diabetes and MI variables were significant for some, but not all, of the differences in weight, height and BMI groups.

Significant differences between measured and self reported values occurred by smoking status for women (height) and men (weight and BMI). Smoking status was significant for height in women, weight in men and BMI in men. Among men, current smokers underestimated their weight less $(p=0.05)$, contributing to a greater over-estimation of BMI ( $p=$ 0.03), than ex- or never-smokers. Among women, current smokers under-estimated their height more than ex- or never-smokers ( $p=$ 0.04 ). Although BMI did not significantly differ between smoking groups for women ( $p=$ 0.21 ), the results had the same rank order as for men. Mean (SD) differences in BMI (measured minus estimated) for men were -0.36 (1.45) for current smokers, -0.16 (1.29) for never-smokers and -0.01 (1.67) for exsmokers. The corresponding values for women were $-0.27(1.31),-0.15(1.37)$ and -0.06 (1.26).
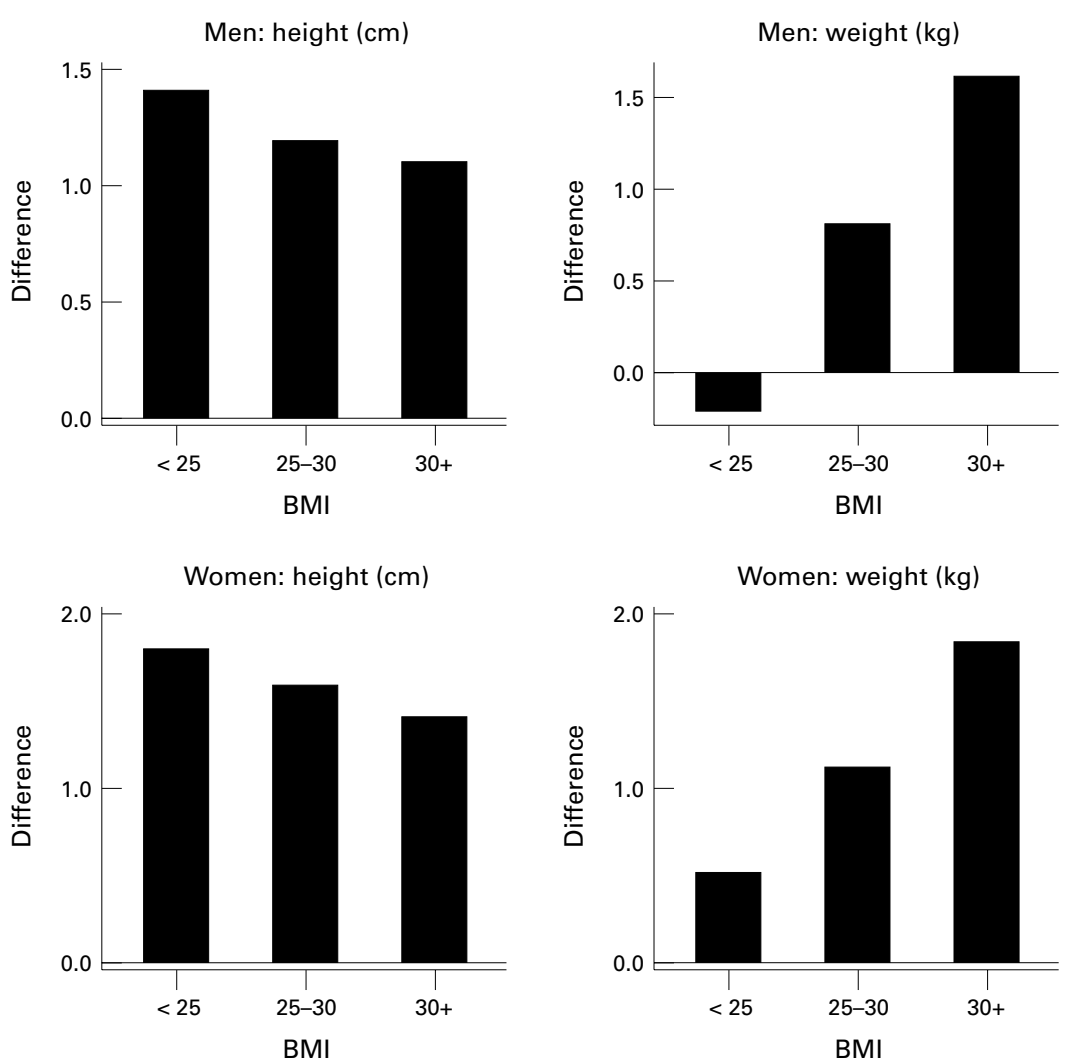

KEY POINTS

- The Scots uniquely under self report height as well as weight, which results in BMI estimates close to the true values.

- Estimates of obesity prevalence (BMI>30), based on self reported height and weight have high sensitivity and specificity for men (respectively $83 \%$ and $96 \%$ ) and women (respectively $89 \%$ and $97 \%)$.

- Obesity prevalence may be successfully monitored in Scotland using self reported data on weight and height and the specifically developed prediction equations.

- The feasibility of developing equivalent equations in other populations is worth considering for cost effective monitoring of obesity prevalence.

Men with diabetes under-reported their weight more than those without $(p=0.09)$ : mean (SD) differences (measured minus selfreported) were 1.9 (1.9) and 0.5 (3.7) for those with and without diabetes respectively. The differences for women, although not significant $(\mathrm{p}=0.47)$, were fairly similar: $1.4(3.1)$ and 0.9 (2.6) respectively.

Women with MI under-reported their height less $(\mathrm{p}=0.04)$ and their weight more $(\mathrm{p}=$ $0.09)$ than those without. As a consequence, BMI was under-estimated in those women
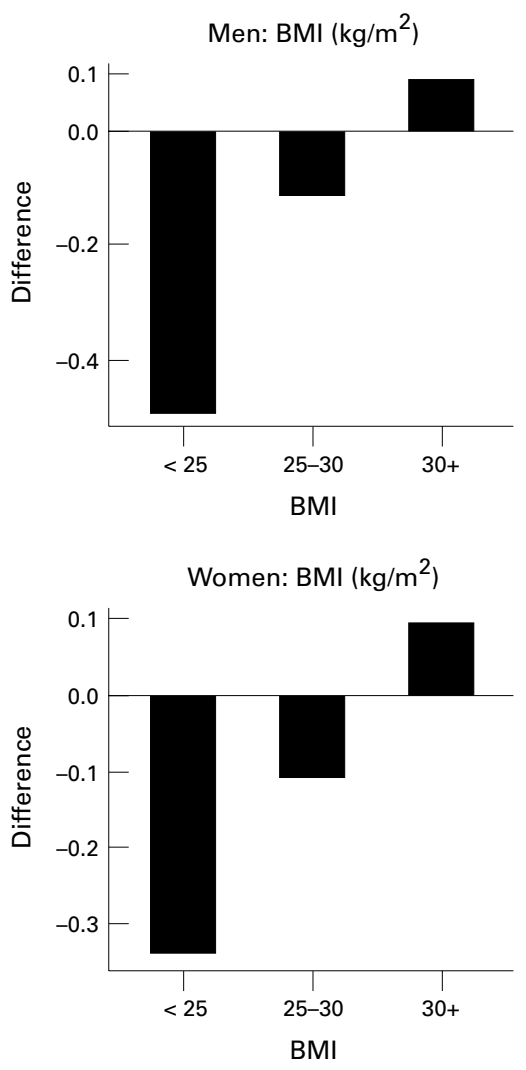

Figure 1 Errors for self reporting of weight and height, and estimated body mass index (BMI, $\left.\mathrm{kg} / \mathrm{m}^{2}\right)$ by true BMI group. BMI groups $<25$ desirable weight; 25-30 overweight; 30+ clinically obese. The difference between true (measured) and self reported weight and height was calculated as measured minus self report. The difference in BMI was calculated as the true BMI (from measured weight and height) minus the estimated BMI (from self reported weight and height). Hence a positive difference $(>0)$ represents under-reporting relative to the true value, and a negative difference $(<0)$ indicates over-reporting relative to the true value. Significant differences (ANOVA) occurred between the errors from self reporting by true BMI group for weight and BMI in both men and women ( $p<0.001$ for all). 
Table 3 Effect of measured (true) body mass index on the difference between measured and self reported height, weight and body mass index after allowing for age, smoking status, occupational social class, education level, housing tenure, myocardial infarct status, diabetes status, cotinine and physical activity ratio

\begin{tabular}{|c|c|c|c|c|c|c|}
\hline \multirow[b]{2}{*}{ Difference } & \multicolumn{3}{|l|}{ Men } & \multicolumn{3}{|l|}{ Women } \\
\hline & Slope (SEM) & $p$ value $\neq$ & $\%$ explaineds & Slope (SEM) & pvalue & $\%$ explainedS \\
\hline Height* & $-0.043(0.026)$ & 0.09 & $4.2 \%(3.7 \%)$ & $-0.034(0.017)$ & 0.05 & $5.1 \%(4.5 \%)$ \\
\hline Weight ${ }^{\star}$ & $0.199(0.037)$ & $<0.0001$ & $6.3 \%(1.7 \%)$ & $0.103(0.021)$ & $<0.0001$ & $6.6 \%(2.8 \%)$ \\
\hline Body mass indext & $0.065(0.015)$ & $<0.0001$ & $5.6 \%(2.6 \%)$ & $0.033(0.010)$ & 0.001 & $6.7 \%(5.0 \%)$ \\
\hline
\end{tabular}

${ }^{\star}$ Measured minus self report. †Value computed from measured height and weight less value computed from self reported height and weight. $\neq \mathrm{p}$ value for body mass index, given all the other variables. $\ r^{2}$ with body mass index included in the model, compared with that without (in parentheses).

Table 4 Number (and percentage) classified into standard obesity groups (by body mass index) using self reported height and weight according to true ${ }^{\star}$ obesity status

\begin{tabular}{|c|c|c|c|c|c|c|c|c|}
\hline \multirow[b]{2}{*}{ True status $\left(\mathrm{kg} / \mathrm{m}^{2}\right)$} & \multicolumn{8}{|c|}{ Status according to self reports } \\
\hline & $\begin{array}{l}\text { Men } \\
\text { Desirable }\end{array}$ & Overweight & Obese & Total & $\begin{array}{l}\text { Women } \\
\text { Desirable }\end{array}$ & Overweight & Clinical obese & Total \\
\hline Desirable $(<25)$ & $251(87)$ & $37(13)$ & $1(0)$ & 289 & $375(91)$ & $37(9)$ & $0(0)$ & 412 \\
\hline Overweight $(25-30)$ & $33(10)$ & $265(83)$ & $21(7)$ & 319 & $32(11)$ & $235(82)$ & $18(6)$ & 285 \\
\hline Obese $(\geqslant 30)$ & $0(0)$ & $26(17)$ & $131(83)$ & 157 & $1(1)$ & $17(10)$ & $145(89)$ & 163 \\
\hline
\end{tabular}

*As computed from measured height and weight.

with MI whereas it was over-estimated in those without MI ( $\mathrm{p}=0.006)$. Although differences in the men were not significant, their estimates followed similar patterns to the women. For men BMI mean (SD) differences (measured minus self reported) were 0.13 (1.48) and -0.24 (1.47) for those with and without MI respectively. The corresponding results for women were 0.57 (1.44) and -0.21 (1.33).

The prediction equations for height and weight, (with standard error in square brackets), and the percentage of variance explained by the equation $\left(r^{2}\right)$, are given below for men and for women:

HEIGHT

$\operatorname{Men}\left(r^{2} 90 \%\right)$

Height $=22.120[2.0545]+0.880$ [0.0130](self reported height) - 0.0435 $[0.0071]($ age $)+0.0217[0.0067]$ (self reported weight)

Women $\left(r^{2} 88 \%\right)$

Height $=18.684[1.953]+0.900$ [0.012] (self reported height) - 0.0422 $[0.0067]$ (age) $+0.0101[0.0058]$ (self reported weight)

WEIGHT

$\operatorname{Men}\left(r^{2} 93 \%\right)$

Weight $=2.485[0.833]+0.979[0.010]($ self reported weight) -0.7086 [0.3084](current smoker $)+0.0993[0.3583]($ ex-smoker $)+$ 1.4034 [0.7856](diabetic)

Women $\left(r^{2} 96 \%\right)$

Weight $=0.8759[0.4393]+1.0006$ [0.0066] (self reported weight)

The equations may be used to predict "true" height and weight from self reported values. Consideration was given to how accurate they were in individuals and in groups. Figure 1 shows height, weight and BMI differences by measured (true) BMI group (using standard groupings ${ }^{18}$ ). In both sex groups, underreporting of height decreased and underreporting of weight increased as BMI increased. True BMI had a greater impact on the under-reporting of weight than on the under- reporting of height. As a consequence, BMI was over-estimated less in the middle BMI group (overweight) than in the lowest (desirable) group, and BMI became under-estimated in the highest (obese) group. Even after adjusting for the effect of all the prediction variables considered above, the differences in measured minus self reported height, weight and BMI varied with true BMI in a similar way, as shown in table 3 .

Table 4 shows the relation between true BMI and that estimated from self reported height and weight. Because, as seen already, the errors in self reports were small the vast majority of people were correctly classified according to standard BMI categories. ${ }^{18}$ For men the sensitivity and specificity for determining clinical obesity were $83 \%$ and $96 \%$ respectively; corresponding figures for women were $89 \%$ and $97 \%$.

\section{Discussion}

This work sought to investigate whether eliciting self reported weight and height by questionnaire was a valid tool for determining the population prevalence of overweight and obesity in Scotland. The MONICA population sample was representative of the north of Glasgow area because a sex and five year age band stratified random sample of 25-64 year olds were recruited and the occupational social class structure was similar to the available census data. The response rate in this mobile population was a respectable $(63 \%)$.

Errors in the measurement of true weight and height were minimised by the strict adherence to the standard operating procedures, and regular calibration of the weighing scales and stadiometre. The subjects completed the questionnaire on self reported weight and height before attending the clinic, and while their study literature included the information that they would be measured, weight and height were only two measurements in a battery of anthropometric and other assessments, including ECG recording and a blood sample, and hence were unlikely to be major foci of 
attention when the self reported weight and height were completed as part of the multifaceted Personal Health Record. As such, a measure of confidence exists that the self reported values were not influenced by the study protocol in itself.

The results of the under reporting of true weight and the strong influence of true BMI on the difference between true minus self report agree with most previous assessments of the accuracy of self reporting. ${ }^{1-3} 5^{5-11}$ The impact of age on the accuracy of self reported weight has been reported previously, ${ }^{1-3}{ }^{5}$ but was minimal in the present population $(\mathrm{p}=0.04$ for women and non-significant for men). Contributing reasons to the general under reporting of weight could be that people weigh themselves at home with few or no clothes on compared with fully clothed (apart from shoes and jackets) at clinic visits. Also weighing scales, even within hospitals and clinics are notoriously inaccurate: however, we have no evidence to suggest that a strong bias exists towards under estimation. An additional explanation for the under reporting of weight is the aspect of body image and the desire to be slim, which is particularly prevalent among women. ${ }^{67}$ Interestingly, none of the three different measures of socioeconomic status (occupation, education level, housing tenure) seemed to significantly influence the accuracy of self reports, suggesting that previous reports of socioeconomic status influencing accuracy of self reporting in other populations ${ }^{2}$ either do not apply in this Scottish population or that these may have been attributable to inadequate adjustment for BMI, age or other factors.

Similarly, neither smoking habit based on cotinine levels, self reported adherence to a special diet nor level of physical activity appeared to influence the accuracy of self reported weight and height in this population. The lack of any effect of cotinine as distinct from self reported cigarette/tobacco use probably indicates that nicotine in itself does not influence recording ability or body perceptions, whereas, sensitivity/awareness of lower body weight in heavy smokers might have given rise to the lower level of under reporting found in men who smoked. Either low self esteem, or simply lack of interest, might conceivably have contributed to the greater under reporting of height in women who smoked compared with those who did not.

The general finding of under reporting of true height in both men and women in all age groups was surprising, because all similar published studies reported varying levels of over estimation of height in their populations. There appears no obvious basis to suggest that these data are false. Conceivable reasons for this unexpected under reporting of height may be that the population concerned have a knowledge of their height from a time before they were fully grown, or that there exists a general lack of concern or disregard for height as "an issue": neither men nor women feel the need to be tall as it carries no social or economic stigma or benefit. Alternatively it could be a manifestation of a different psyche or outlook on life compared with other nationalities or alternatively of low self esteem. Under-reporting of height was least in the older age group, a finding that might have been influenced by actual loss of height with aging. Interestingly, although the results are discordant, this same explanation could have contributed to the increasing over-reporting of height with age in a Swedish population. ${ }^{5}$

The previous studies that found underreported weight and over-reported height have led to a number of articles decrying the use of self reported measures of obesity prevalence because of the chronic under reporting that occurs, and particularly the bias in the elderly and those with a higher $\mathrm{BMI}^{12}$ : Roberts ${ }^{3}$ reported underestimation of obesity prevalence in men of $4.5 \%$ and $6.7 \%$ in women. Although in the current study population, underreporting of weight was directly associated with obesity, the unique under recording of both weight and height meant that the net effect on estimated BMI was negligible (in fact average BMI was slightly over estimated). The specificity of $96-97 \%$ for detecting obesity was equivalent to other studies, while the sensitivity was far higher at $83 \%$ for men and $89 \%$ for women compared with $74 \%$ in the USA, ${ }^{2} 57 \%$ in Spain ${ }^{1}$ and $55-61 \%$ in Sweden. ${ }^{5}$ This high sensitivity and specificity for determining obesity, in both men and women, suggests that eliciting self reported weight and height by postal questionnaire does seem a viable method for determining obesity prevalence in this population. However, it would not be suitable for obesity assessment of an individual in a clinical setting.

The prediction equations derived from these data clearly need testing in other Scottish populations. If such testing proves satisfactory, this would confirm the uniqueness of the Scots for being "self depricating" about their height, as well as "optimistic" about their weight. If this is indeed the case then regular assessment of obesity trends in Scotland by self reporting of weight and height would be a very cost effective way of monitoring health trends towards "The Health of the Nation" and Scottish health targets. ${ }^{19}$ Other countries may wish to consider the feasibility of developing and testing similar calibration equations for the population monitoring of obesity prevalence.

Funding: this work was funded by the Scottish Office Department of Health. All opinions expressed are those of the authors, not necessarily those of the SO:DH

Conflicts of interest: none.

1 Alverez-Torices JC, Franch-Nadal J, Alverez-Guisasola F, et al. Self-reported height and weight and prevalence of obesity. Study in a Spanish population. Int f Obes 1993;17:6637.

2 Nieto-Garcia FJ, Bush TL, Keyl PM. Body mass definitions of obesity: sensitivity and specificity using self-reported weight and height. Epidemiology 1990;1:146.

3 Roberts RJ. Can self-reported data accurately describe the prevalence of overweight? Public Health 1995;109:275

4 Crawley HF, Portides G. Self-reported versus measured height, weight and body mass index amongst $16-17$ year old British teenagers. Int $\mathcal{F}$ Obes 1995; 19:579-84.

5 Bostrom G, Diderichesen F. Socioeconomic differentials in misclassification of height, weight and body mass index based on questionnaire data. Int f Epidemiol 1997;26:8606.

6 Giles E, Hutchinson DL. Stature- and age-related bias in self-reported stature. $\mathcal{F}$ Forensic Sci 1991;36:965-80. 
7 Nichter M, Nichter M. Hype and weight. Med Anthropol 1991;13:249-84.

8 Gupta MA, Schork NJ, Dhaliwal JS. Stature, drive for thinness and body satisfaction: a study on males and females from a non-clinical sample. Can 7 Psychiatry 1993;38:5961.

9 Ziebland S, Thorogood M, Fuller A, et al. Desire for the body normal: body image and discrepancies between self reported and measured height in a British population. $f$ Epidemiol Community Health 1996;50:105-6.

10 Hill A, Roberts J. Body mass index: a comparison between self-reported and measured height and weight. 7 Public Health Med 1998;20:206-10.

11 Kuskowska-Wolk A, Karlsson P, Stolt M, et al. The predictive validity of body mass index based on self-reported weight and height. Int $\mathcal{F}$ Obes 1989;13:441-53.

12 World Health Organization Principal Investigators (prepared by Tunstall-Pedoe H). The World Health Organiza- tion MONICA Project (monitoring trends and determinants in cardiovascular disease): a major international collaboration. F Clin Epidemiol 1988;41:105-13.

13 Woodward M, Tunstall-Pedoe H, Smith WCS, et al. Smokng characteristics and inhalation biochemistry in the Scottish population. F Clin Epidemiol 1991;44:1405-10.

14 Office of Population Censuses and Surveys. Classification of occupations. London: HM Stationery Office, 1990.

15 James WPT, Schofield EC. Human energy requirements. Oxford: OUP, 1990

16 Woodward M. Epidemiology: study design and data analysis. Boca Raton: Chapman and Hall/CRC, 1999.

17 Woodward M, Bolton-Smith C, Morrison C. Errors in selfreported height and weight. Proc Nutr Soc 1999;57:135A.

18 Garrow JS. Treat obesity seriously: a clinical manual. Churchill Livingstone, Edinburgh 1982.

19 The Scottish Office. Scotland's Health: A challenge to us all. Scottish Office Department of Health, Edinburgh 1993. 